\title{
TRACING OUR STEPSIS RETRACING THE EVOLUTION OF EDUCATION AN ALTERNATIVE?
}

\author{
Anamika Das \\ Symbiosis School for Liberal Arts, India, anamika.das@ssla.edu.in
}

\begin{abstract}
In the twenty first century, after 68 years of independence, India is still lagging behind in terms of achieving quality education in the region. Unavailability of proper schools, teaching staff and lack of proper implementation of rules are administrative and legal problems that are often paid attention towards with corrective measures and may show improvement in the years to come. But, flaws beyond administrative and legal obstacles that lay in the philosophy and ideology of the education system of the country are giving rise to a fall in its quality and must also be taken into serious consideration. Students unable to choose educational streams of their choice or schools evaluating students solely on the basis of rote learning, without any thought involved in assignments are basically ideological problems that are more deep-rooted and difficult to eradicate as compared to the administrative ones. Following the same line of thought, the paper traces philosophical theories stated in the past that contain alternatives to eliminate some ideological problems in education in today's era. A progressive move in the field of education would mean coming up with new alternatives. However, if the older philosophical theories that were stated billions of years ago provide us with alternatives for today, then retracing the past being more pragmatic, must be followed, which would include retracing the philosophical theories put forth over time, so that education encourages the flourish of human resource in the country in a comprehensive way.
\end{abstract}

Keywords: national independence, rote learning, philosophical theories, human resource

\section{INTRODUCTION}

Evolution as a concept has several implications in it. It comprises advancement, growth and gaining in a new identification of a particular phenomenon. At present, obstacles are created in instances when students are often pressurized by their parents due to a social hierarchy created, in which a particular discipline may gain preference over the others or the dominance of rote learning during school education may increase, giving rise to inefficiency. Even though they occur in contemporary times, many philosophical notions have been expressed since time almost began by popular thinkers and figures, in India and outside its geographical boundaries, stating their thoughts against these obstacles already. Perhaps, if we trace our steps, the solutions to such problems can be found when we peep into the minds of the oldest thinkers.

The education systems around the world carry some basic philosophical foundations while designing and framing the structure and policies of the education system of a country. The philosophical foundation may act as a charter of solutions for the obstacles arising in the present and the future of the education system. In India, the philosophical theories, be it be laid down by the Hindu religious scriptures (the Hindu religion being mentioned as it is practiced by the majority in the country) or the ones left behind as results, observations and theories of the educational experiments conducted by 
venerated Indian figures, like Kautilya, Tagore or Gandhi, education has been looked at, under a spiritual light. The basic purpose of education in the earliest scriptures has been attaining Moksha or the highest form of freedom. As against this motive, theories under psychology and colonial studies reflect that the west mostly focuses upon attaining materialistic contentment through education and work, giving importance to service for the society at the same time. However different, both the worldviews emphasized on the development of morality within an individual.

The Gurukul system that existed in India, where the student was completely the teacher's responsibility for a certain span of time, did leave a profound effect on the student making him wellrounded and experienced. The individual would often grow, well versed in several disciplines. But perhaps, the worldview obtained by the shishya through this system was very limited due to being taught by one single Guru, and thereby a single perspective. Also most importantly, the system did not allow questioning and challenging the Guru overtly. This of course, does not mean that our country never had traditions which combined arguments and consensus within the higher learning process. The Buddhist philosophy and concept of sanghs had their very identity in the concept of consensus where any form of teaching or any form of decision making was performed after discussions and reaching a consensus making the process intensely participative. Within Nyaya, any and every form of learning and teaching was crafted through discussions, which also included certain forms of arguments. Above everything, the Upanishadic system, the very core of the Indian environment of learning involved and encouraged intense dialectics, deduction, induction and discussions in its educational set-up, giving birth to and raising deep and intense deliberators.

This rich element of discussions and consensus, leading to deliberations that constituted the philosophy of Indian education was washed away as India became a land of the colonized people. Perhaps with a blend of the tradition of the Gurukul system and the period of colonization, giving rise to an ideological establishment of a master-slave concept eliminated the traditions of questioning and challenging. Hence, one of the most important problems in the education system today is a result of this blend. Absolute subservience in front of authority or fear of negative reinforcements still play their parts, giving rise to hesitation in voices and blockage in thought processes, creativity and novelty often trapping the real spark of the human resource.

\section{THE MAJOR OBSTACLES TODAY}

Very often we come across children who do very well during their schooling but fail to perform well in college due to change in environment and curriculum. It is also not necessary that very efficient performers in their college and university, will get positive appraisals at workplace either. Strength at its peak during specific sections and not during the other sections of life may carry a lot of reasons. It may either mean that we as individuals make the wrong choices or that the basic skills required in order to adapt to different levels in our lives and perform considerably well in most situations is lacking. It clearly means that the education system is not built in a way where individuals go through the development of a soul that is flexible and accommodating. In this system, somewhere individuals are groomed in ways by which they do not quite obtain the ability to think, analyze and create something novel, but just grasp and reproduce what exists already. Perhaps it is too idealistic to expect a foolproof system, but at least the goal of the very concept of imparting education should encompass raising moral and ethical individuals. These individuals would then emerge well versed with the ability to learn, adapt and create without much conflicts, taking place both internally and externally.

Other major potholes can be observed in the conventional evaluative measures that is solely based on rote learning from texts made available to the students. Gathering of facts and figures within the four walls of the classroom, without acquiring practical and real life experiences cannot give rise to an impactful learning, necessary for the society as a whole.

\section{THE RETRACING OF THE EVOLUTION IN EDUCATION}

In contrast to the scene of pressure, stereotypical judgements and evaluations taking place on the basis of rote learning solely, The Greek philosophers during 450 B.C.E, started stating concepts in education that would negate all the negative repercussions that the rote learning system in particular, brings us today. For instance, when the society was not as advanced as today and modern technology was not even a spark in its founder's eye, Greek philosopher Plato, had stated education to be one of the three major pillars of an ideal state. In his education system, the early childhood has to be dedicated to anecdotes and moral stories which would enhance the ethical behavior in a person at an age where the mind is most flexible. Late childhood, the entire adolescence and very initial stage of adulthood have been characterized mainly by gymnastics and music. Gymnastics has been 
emphasized upon for physical development and wellbeing. Music, very different in essence from the current idea of music, which also included poetry, drama, dance and forming and studying of tunes and rhythms has been stressed on for mental development and wellbeing. Today, hardly any schools have disciplines in their curriculum, which are made mandatory for explicit physical and mental development. It is certain that a very few schools have a serious discipline structured in the field of sports, music or any discipline that actively promotes physical wellbeing for each and every student, mandatorily.

Advancing the thought beyond just development and wellbeing, Greek philosopher Aristotle threw light on the deeper advantages of indulging in physically vigorous activities. According to the philosopher, gymnastics not just develops a sound body and physique, but also develops sportsmanship that is essential for life. Today, enormous cases related to suicides, depression, bipolar mood disorders come up every day, suggesting a decline in the ability to face challenges, difficulties or failure among the young generation. Currently, when any educational institution is attended, the sole motive is to gain a degree for job, which is believed to provide with a comfortable and happy living in the future (indeed following the western purpose in the educational philosophy, but lacking the entirety of service as citizens). Education in order to gain knowledge and maintain ethical standards has become secondary if not the last motive for acquiring education. Aristotle also very meticulously pointed out towards the morality aspect of education that must be gained by an individual. Education has become an object through which an individual is judged, critiqued and pressurized on, minimizing the concept to the level of mere numerical values or grade points. Hence, character building and the ability to analyze choosing difficult but correct ways through education has lost its position from being at the priority which often show results today. Several students, irrespective of obtaining above average scores in their educational institutions face difficulty while confronting the world beyond the gates of those institutions.

Not just western philosophers, but also modern figures from India, such as Mahatma Gandhi, Rabindranath Tagore and Shri Aurobindo, have all stressed upon imparting of education as the very foundation of creation and development of a society. M.K Gandhi with all the difficulties, obstacles, planning and struggle that surrounded him during the freedom struggle, had always emphasized on the inculcation of a comprehensive education system, "Where children grow in body, mind and spirit". He also stressed upon the importance of fine arts as a unique and important element of education where the mind opens at a different level while the hands are engrossed in creation. According to him, due to a blind idealization of western education, the most traditional ways of imparting education, which included extracting knowledge and experiences from the most real aspects of nature was suppressed. The class room stopped being a reflection of the real world, with the kind of education that may or may not be beneficial in life ahead.

Similar ideas were put forth by Kabiguru Rabindranath Tagore, who believed that education without gaining an experience of the natural world around us, translates to gaining in of knowledge "in proxy". A man cannot be fully educated if his soul is deprived of the most essential values and wisdom. Tagore's educational experiment that can be seen even today in his institution called Vishwabharati in Shantiniketan, West Bengal, where he attempted and succeeded in initiating and maintaining an institution that connects a student with nature during the process of learning. He also believed very strongly that in a bid to obtain uniformity and win the competition in terms of receiving education, people often forget the growth of the individual himself, which can occur the most in the natural environment that surrounds us.

\section{THE CONTRAST- DIFFERENT PATHS, DIFFERENT REGIONS, BUT THE SAME DESTINATION}

As is evident, where on one hand, the earliest of Greek philosophers emphasized on an overall development with exposure to various disciplines in practical ways with morality moving in parallel, Indian thought and traditions also rest enormous importance with the overall development of an individual with an exposure to the real world within the notion and practice of morality. Although different paths, the destination is to gain a rich educational experience where the individual recognizes himself/herself and the others around and goes through a process of comprehensive development. This proves that as time has progressed and boundaries have been transcended, people have devised dynamic ways of imparting education, but, the destination has been the same and has shown positive results.

Education system in India, with a generic overview today, lacks every element that the earliest thinkers have put forth. Policy makers and thinkers have restricted children to the four walls of the 
classroom, which all the four thinkers mentioned above, have shown an opposite stance towards. Change due to the progress in time does not mean that we forget the legacies we have had. Today, the ultimate aim has been restricted to the maximization of personal- material pleasure. However, human resource of a country will be able to reach its zenith, only when they recognize and gain knowledge about themselves, as a foremost priority, rather than learning by rote and being evaluated on facts, figures and analysis done by others.

\section{THE ALTERNATIVE}

Hence, the education system should be crafted or recreated, with blend of the theories and beliefs of the thinkers from the oldest to the contemporary times. In this way, the body, mind and spirit of individuals develop hand in hand. Sports, gymnastics, dance and similar activities that result in a healthy and sound body and sportsmanship (in case of sports) in order to reach the readiness to face challenges and gain a balance between the mind and body must be imparted as an important discipline mandatorily for every student. This should be done striking a balance in terms of importance with disciplines like mathematics or grammar. Such disciplines in the education system would also step beyond the concept of evaluation on the basis of rote learning, where the students just grasp and reproduce, and would act as a catalyst for the students where they would think, create and produce.

Today, due to relative amount of job guarantee and a stereotypical judgement on a person's smartness based on his/her efficiency in mathematics and hard sciences, children are often pressurized to select subjects according to their parents' whims. The whims may or may not coincide with the student's aptitude and choice. Choosing and practicing professions on the basis of choice was emphasized by both Plato and the Indian philosophy in the early Vedic age. Plato introduced the concept of aptitude keeping a foundation of the tripartite soul introduced by Pythagoras. In his concept of education, post the anecdotal and musical cum physical education, a personality test conducted would throw some light on the kind of profession - reason, spirit and appetite (drawn from the tripartite soul), a person shows an inclination towards. According to the results, the person would be placed in the respective field, in which he/she would serve the state with all his/her dedication. The early Vedic age in Indian philosophy did not even emphasize on aptitude, as much as it emphasized on a person's individual choice to practice his/her own occupation. It is only later that the caste system restricted occupations based on the Hindu Varna system and at present, societal pressures and people's opinions climb a pedestal, much higher than the student's comfort and aptitude. Parents often try to live their dreams through their children without realizing that their children are individuals themselves who must gain education for themselves.

\section{Anti-thesis and Synthesis}

Of course it may seem unreasonable to quote examples from the past as Plato and Aristotle had certainly formulated ideas in their time and context, which may or may not work out in today's context. The very fact that we have moved ahead in time, must not imply that old ideas should be forgotten and instead only new ideas must be welcomed and applied. For what matters in the end is what brings us better results, even if it means retracing our steps and going through the evolutionary methods in terms of the concept of education. Also, the resources that would be required for such a seemingly grand and idealistic form of education system is a huge matter of concern, especially for developing countries like India. The solution is to make gradual changes. Such transformations cannot occur overnight. Also, there is often a difference between what is proposed on paper, and what is followed in practice. The basic idea is that the ultimate destination of an education system, must mostly take into consideration, the overall development of the human resource of the nation. Morality, self-realization and gaining real life experiences, with a number of different disciplines being taught in the classroom, must be blended with theory and facts for the individual to have a wide visual and cognitive field. Lessening of unreal and artificial resources for education, and increasing of real life elements in the education system can only mean lowering of expenses in materially expensive resources, benefiting the resource providers and increasing affordability by the people. So, a blend of ideas by taking regressive steps, brought forth with time, which aids the flourish of spirituality, mentioned by both Gandhi and Tagore and the knowledge within an individual may have more advantages than disadvantages and may be easier in practice, than as an ideology.

\section{CONCLUSION}

In the present era due to the problem of overpopulation in India, both parents and children have been blinded by the idea of competing. There is cut - throat competition in every field of discipline and career, coercing sweat droplets on the foreheads of many. However, is education a concept that 
should be solely based on competition and status in the society? Due to this state of the society we live in, the original motive of the very concept of education has disappeared up to a large extent. The motive has always comprised focusing upon a comprehensive developmental system that focuses on both the self and the the society as a whole. If potholes in the current structure can be repaired by tracing our steps in the field of education, then perhaps a regression in the evolution of education rather than advancement is the perfect alternative.

\section{REFERENCE LIST}

By Gender, Age-Cohort and Location, Center Discussion Paper, No. 815. USA

Duraisamy, P. (2000): Changes in Returns to Education in India, 1983-94

Gandhi, M.K (1933): Towards new education. Bharatan Kumarappa edition. India.

Geeta Gandhi Kingdon (2007): The progress of school education in India. Global Poverty Research Group. ESRC. U.K.

Tagore, R (1933): My School. Macmillan. United Kingdom

Talip Kabadayi. (2013): Aristotle: on virtue education. Pamukkale University. Turkey 